\title{
COMPARISON OF BRONCHODILATOR EFFECT OF SALBUTAMOL DELIVERED VIA MDI AND DPI IN COPD PATIENTS
}

\author{
Shrestha $R,{ }^{1}$ Shakya $R^{2}$ \\ 1 Lecturer, Department of Pharmacy, Asian College for Advance Studies, Nepal \\ ${ }^{2}$ Asst. Prof. Kathmandu University, Nepal.
}

\begin{abstract}
Introduction : Chronic Obstructive Pulmonary Disease (COPD) is one of the leading problems affecting majority of population all over the world which diminishes the quality of life of the individual and create extra burden to the society as well as country. Inhaled bronchodilator therapy is the mainstay of treatment in the management of COPD. Various inhaled [e.g. metered dose inhaler (MDI) /dry powder inhaler (DPI)] formulations are available and are widely used among the COPD patients in Nepal.
\end{abstract}

Methodology : This is cross sectional prospective study, designed to compare the bronchodilating effect produced when salbutamol is delivered via two devices: MDI (Asthalin® from Cipla) and DPI (Asthalin $®$ rotacap delivered via Rotahaler $®$ from Cipla), in patients with stable COPD. It is proven by previous studies that intervention is necessary to improve the compliance of the patients; all subjects (total $n=60 ; 30$ in each group) are counseled and trained to follow correct inhaling technique through particular device. Then their improvements in lung function were measured with reference to the pulmonary function test based on spirometry.

Results : Patients enrolled in each group were not statistically different regarding to age $(P=0.318)$, weight $(P=0.324)$ \& $\mathrm{BMI}(\mathrm{P}=0.836)$. Among the total subjects $87 \%$ had smoking history and $2 \%$ were still smoking and there was no significant difference in smoking habit between the two groups ( $p$-value $0.544>0.05$ ). Similarly $91.6 \%$ of the total had exposure to indoor air pollution which had been the major risk factor for COPD. Most of the patients were on stage II COPD (62\%). Salbutamol was found to have no effect on vital statistics of patients. Study showed there was no significant difference in the improvement of forced expiratory volume in one second (FEV1) $(p=0.802)$, FVC ( $p=0.693), F E V 1 \%(p=1)$ and PEF $(p=0.448)$ between MDI and Rotahaler groups. Major side effect associated with the MDI users is headache $(79 \%)$ while those among Rotahaler users were muscle cramps (79\%). Even though intervention improved the inhaler using technique among the patients in both the groups, it was found even after counseling, DPI seemed to be better understood by the patients in comparison to MDI ( $p=0.003 \& 0.00)$. In addition DPI was preferred by most of the patients who were familiar with both delivery systems. It was also found to be cheaper than the MDI.

Conclusion : Overall evidence suggests that although both MDI \& DPI improve the lung function of COPD patients to similar extent, DPI is cheaper and more preferred and can be easily handled by the patients which can result in reduction of non-compliance.

Keyword : COPD. Salbutamol, DPI, MDI, Spirometry

\section{INTRODUCTION}

COPD stands for Chronic Obstructive Pulmonary Disease. ${ }^{1}$ Chronic obstructive pulmonary disease is a lung ailment

\section{Correspondence to}

Renu Shrestha (Dhungel)

Department of Pharmacy, Kathmandu University that is characterized by a persistent blockage of airflow from the lungs which is an under-diagnosed, life-threatening lung disease that interferes with normal breathing and is not fully reversible. ${ }^{2}$ COPD is not one single disease but an umbrella term used to describe chronic lung diseases that cause limitations in lung airflow; the more familiar terms are 'chronic bronchitis' and 'emphysema'. ${ }^{3}$ 
According to the latest WHO estimates (2007), currently 210 million people have COPD and 3 million people died of COPD in 2005. WHO predicts that COPD will become the third leading cause of death worldwide by $2030{ }^{3}$

In Nepal, a combination of asthma and bronchitis constitutes a major cause of mortality. ${ }^{4}$ It is estimated that about 7500 people, most of whom are children, lose their lives each year in Nepal due to indoor air pollution (IAP) related Acute Lower Respiratory Infections (ALRI) and COPD. ${ }^{5}$

COPD can not be cured, but it can be controlled. ${ }^{1}$ Prevention of disease progression, improvement of symptoms, exercise tolerance and health status and decrease in exacerbations and mortality are the goals of management. ${ }^{6}$

The inhaled route is preferred in the therapy of COPD as small doses of drugs are delivered direct to their site of action, leading to a rapid onset of action and a low incidence of side effects. ${ }^{7}$ The airways are treated but less drug reach to the other parts of the body. ${ }^{8}$ Inhaled medications are intended to exert localized, site-specific therapeutic effects on the bronchioles. ${ }^{9}$ Thus inhaled bronchodilator therapy is the mainstay of treatment in the management of COPD. Inhaled short acting bronchodilator is recommended for symptoms in mild disease, whereas inhaled long acting bronchodilator is recommended for maintenance therapy of daily symptoms. ${ }^{6}$

The effectiveness of inhaled bronchodilator in individual patients is assessed by comparing measurements from pulmonary function tests made before and after administration of the drugs. ${ }^{10,11}$ Generally, forced expiratory volume in one second (FEV1) is the marker used, in line with the Global Initiative for Chronic Obstructive Lung Disease (GOLD) guidelines. . $^{12,13}$

Various inhaled formulations [metered dose inhaler (MDI) / dry powder inhaler (DPI) or Nebulizer] are available but it is the MDI, which is most commonly prescribed. ${ }^{14} \mathrm{Although}$ nebulizers are frequently used to deliver COPD treatment, particularly to less mobile patients, most current designs are bulky and inconvenient, and treatment times are longer. Therefore, they are better categorized as fallback devices for most COPD patients. They are not true competitors to pressurized metered-dose inhalers (pMDIs) and DPIs for outpatient use..$^{15}$

There is no perfect inhaler, and each has advantages and disadvantages, but there is increasing recognition that a successful clinical outcome is determined as much by choice of an appropriate inhaler device as by the drugs that go in them. ${ }^{16}$ Drug delivery from all inhaler devices depends on how the patient prepares the device and then inhales from it. The best device for COPD patients is arguably one for which both these steps can be performed successfully without major challenges.

There is evidence that a patient is most likely to use correctly an inhaler that he or she prefers. ${ }^{17}$ Choice of an inhaler device should therefore take into account the likelihood that patients will be able to use a particular device correctly, cost-effectiveness, preference and likely compliance.

This is significantly important to compare the cost and benefit between MDI and DPI for patient with COPD to achieve the definite therapeutic outcome. Hence the study is mostly focused on to analyze the device preference of the patients and their capability of producing improvement in pulmonary function.

\section{METHODS}

\section{Study Design}

This was cross sectional prospective study.

\section{Study Site and duration}

The study was conducted in Dhulikhel Hospital, Kathmandu University Teaching Hospital, Dhulikhel from Dec 2007 to June 2008.

\section{Sample selection criteria}

Patients from out patient department as well as from in patient department who had age above 15 years with the documented diagnosis of COPD and prescribed with salbutamol inhaler (200 $\mu \mathrm{g}$ dose) were included in the sample. However patients with following criteria were excluded in the sample.

- Unstable angina

- Recent pneumothorax

- Recent heart attack or stroke

- Recent eye or abdominal surgery

- Coughed up blood recently and the cause is notknown

- Patient prescribed with corticosteroids 


\section{Sample size}

Sixty $(n=60)$ consecutive patients who fulfilled the inclusion criteria were included in the study. All patients were then further divided into MDI and DPI groups (thirty in each group) according to the type of salbutamol inhaler they were prescribed with as well as on their own preference if they were familiar with both inhalers.

Each patient of MDI group ( $n=30)$ received $200 \mu \mathrm{g}$ (two puffs in one minute interval) salbutamol four times a day via a MDI (ASTHALIN CFC free inhaler, Manufactured by CIPLA, Ltd. INDIA containing 200 Metered dose and each puff containing $100 \mu \mathrm{g}$ of Salbutamol) as per MDI score technique .While patients of DPI group $(n=30)$ received $200 \mu \mathrm{g}$ of salbutamol via Rotahaler (ASTHALIN Rotacap, Manufactured by CIPLA, Ltd. INDIA; each Rotacap containing $200 \mu \mathrm{g}$ of Salbutamol for use with Rotahaler) four times a day as per DPI scores technique.

\section{Data Collection}

At first, patients who met the inclusion criterias, were told about the study being done and about their contribution in this study. After taking informed consent from the patients, they were directly interviewed using structured questionnaire. The key data information included age, sex, literacy, occupation, races, smoking/ alcohol habit and exposure to any air outdoor or indoor air pollution. Additional information about date of diagnosis of COPD, drug treatment for COPD and other concomitant diseases and abnormal clinical findings were recorded from medical case record.

Patients were counseled about how to use the inhaler they were prescribed with, for those who were using inhaler for the first time. For those who were already using inhaler, knowledge about using technique of particular inhaler (MDI or DPI) was checked. If they did wrong they were counseled and demonstrated (using device without active ingredient) how to use it correctly. The improvement in inhaler using technique was evaluated by scoring each correct step using Rotahaler/ Meter Dose Inhaler Technique Score Chart just after counseling and also on follow up.

After counseling, spirometric test was performed in each patient by using the spirometer (Vitalograph) to find out the baseline lung functions. If the patient was already using the salbutamol inhaler, after consultation with the physician, the patient was made to escape the dose of the medicines $6 \mathrm{hrs}$ before the spirometry evaluation to get the baseline results.

During the spirometric test each patient was asked to take the deepest breath he/she could, and then to exhale into the sensor as forcefully as possible and for as long as possible. During the test, soft nose clip was used to prevent air escaping through the nose. The present lung functions of the patients were displayed in terms of FVC (Forced Vital Capacity) (Liters), FEV1 (Liters) and PEF (Liters/ second). Standard values for each patient differ according to their height, age, sex, and sometimes race and weight. After the baseline evaluation, the usual dose i.e. $200 \mu \mathrm{g}$ of salbutamol was given to the patients at the same time his/her inhalation technique was also checked and then spirometric analysis was repeated as follow up to find out the improvement in lung function.

The blood pressure (BP), respiration rate (RR), pulse rate (PR) and potassium level were also assessed before and after the use of bronchodilator to find out if there was any change. The spirometric test, vital statistics (BP, RR, PR), potassium level, understanding of inhalation technique, health problems they faced during therapy were again investigated in follow up visit after two weeks (usually 1420 days) of each patients of both groups.

\section{Data analysis}

The data collected by using structured questionnaire and reviewing medical record forms were entered into a computer file and were expressed into codes for the purpose of analysis. The data with qualitative variables were summarized and expressed as frequency and percentage. The data with quantitative variables were expressed as mean and standard deviation (SD) and were analyzed by using statistical tests.

Patient's age, weight, height and BMI were compared using Mann-Whitney $U$ test. Change in Vital Statistics $(B P, R R, P R)$, potassium level and improvement in lung function parameters (FVC, FEV1, FEV1\%, PEF) after using salbutamol via particular inhaler (MDI or DPI) were analyzed by Wilcoxon Signed Ranks Test. While comparison of same variables including oxygen saturation between two different groups was carried out by using Mann-Whitney $U$ test. $\mathrm{MDI}$ and DPI scores were compared for the values before counseling, after $30 \mathrm{~min}$ of bronchodilator and after two weeks of starting bronchodilator by using Mann-Whitney $\mathrm{U}$ 
test. All data were analyzed at the $5 \%$ significance level.

The data were significant for $p<0.05$. All analysis was done by using statistical software SPSS 15 and graphs were plotted in Excel 2003 and 2007.

\section{RESULTS}

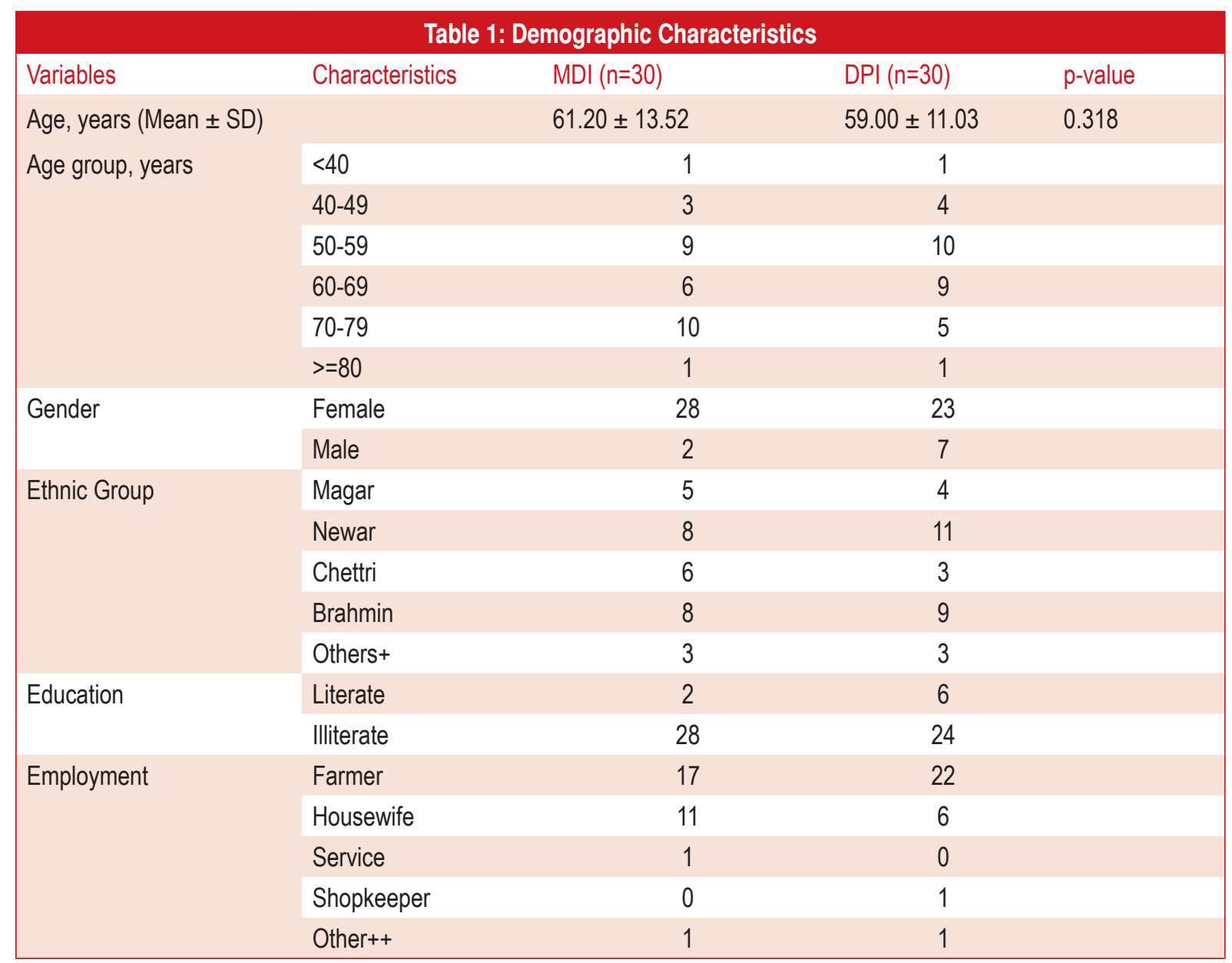

Others+: Rokka, Giri, Pariyar, Lohala, Shanker, Thokar; Other++: Masson, Student

\begin{tabular}{|llll|}
\multicolumn{5}{c}{ Table 2: Anthropometric Measurements } \\
\hline Variables & MDI $(\mathrm{n}=30)$ & $\mathrm{DPI}(\mathrm{n}=30)$ & P-value \\
Weight $(\mathrm{Kg})$ & $44.83 \pm 9.27$ & $46.57 \pm 7.22$ & 0.324 \\
Height $(\mathrm{cm})$ & $148.77 \pm 6.17$ & $152.6 \pm 7.11$ & 0.049 \\
BMI status $\left(\mathrm{kg} / \mathrm{m}^{2}\right)$ & $20.27 \pm 3.97$ & $19.77 \pm 2.81$ & 0.836 \\
Under weight $(\mathrm{BMI}<18.5)$ & 11 & 10 & \\
Normal weight(BMl 18.5-24.9) & 16 & 18 & \\
Overweight(BMl 25-29.9) & 1 & 2 & \\
Obese(BMI $\geq 30)$ & 2 & 0 & \\
\hline
\end{tabular}




\section{Smoking Status of the Subjects}

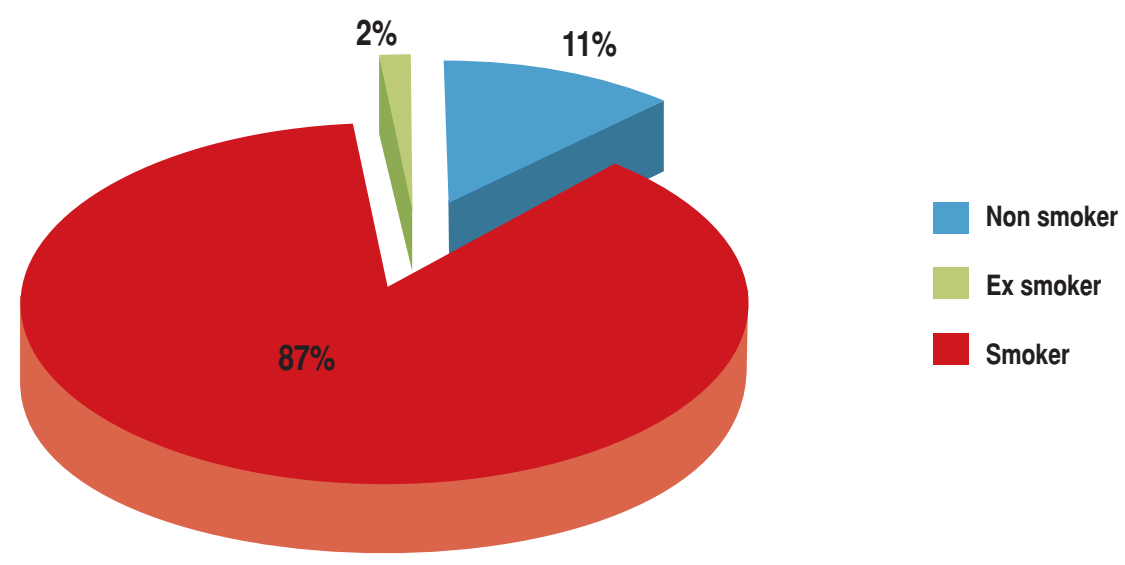

Smoking Habit according to consumption

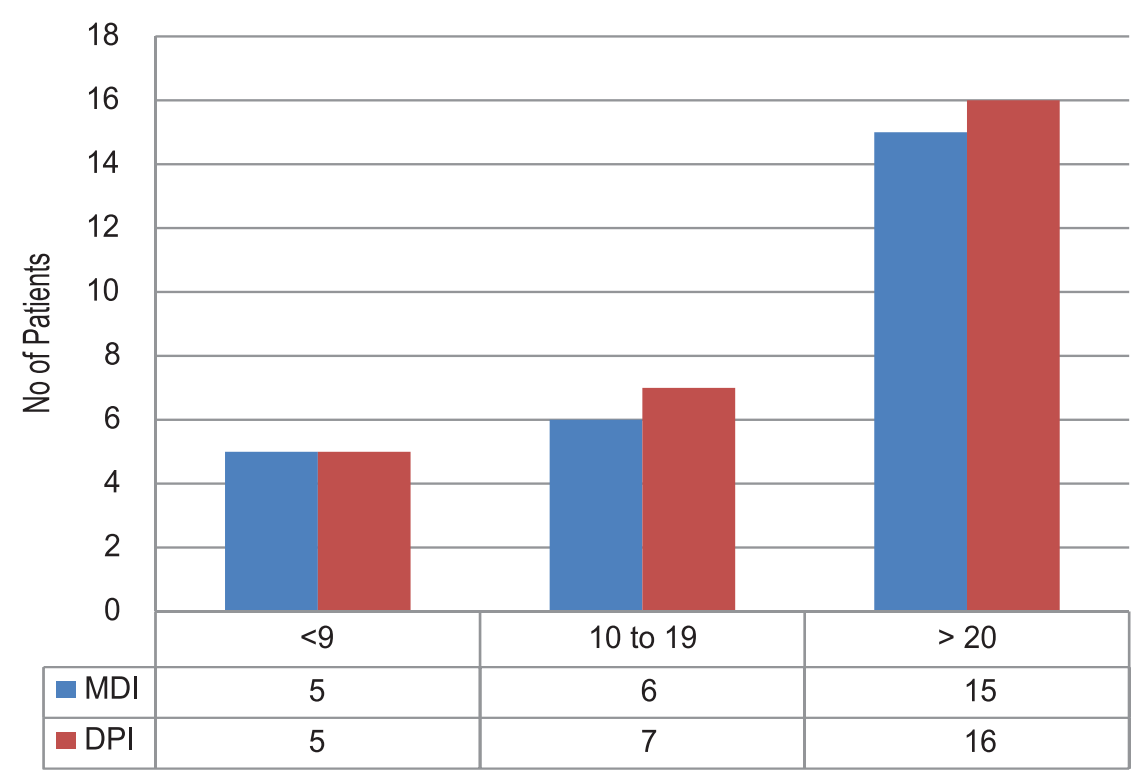

Figure 1: Smoking habit

\section{Study of vital statistics of the participants}

Table 3: Comparison of vital statistics and oxygen saturation of the participants between two groups i.e. MDI \& DPI (Mann-Whitney U)

\begin{tabular}{|l|l|l|}
\hline Measures & MDI - P-values & DPI - P-values \\
\hline$\Delta \mathrm{SBP}$ (after 30 mins) from baseline & 0.227 & 0.414 \\
\hline$\Delta \mathrm{SBP}$ (after two weeks) from baseline & 0.068 & 0.157 \\
\hline$\Delta \mathrm{DBP}$ (after 30 mins) from baseline & 0.234 & 0.107 \\
\hline$\Delta \mathrm{DBP}$ (after two weeks) from baseline & 0.36 & 0.19 \\
\hline$\Delta \mathrm{RR}$ (after 30 mins) from baseline & 0.395 & 0.011 \\
\hline$\Delta \mathrm{RR}$ (after two weeks) from baseline & 0.011 & 0.039 \\
\hline Change in mean value of PR & $\mathrm{MDI}$ & $\mathrm{DPI}$ \\
\hline
\end{tabular}




\begin{tabular}{|l|l|l|}
\hline Before medication & $89.2 \pm 14.97$ & $86.23 \pm 12.86$ \\
\hline After 30 mins & $87.87 \pm 14.19$ & $85.57 \pm 0.58$ \\
\hline After two weeks & $83.2 \pm 8.67$ & $82.6 \pm 8.39$ \\
\hline
\end{tabular}

$\Delta=$ change from baseline after bronchodilator therapy, $\mathrm{SBP}=$ Systolic blood pressure, $\mathrm{DBP}=$ Diastolic blood pressure, $\mathrm{RR}=$ Respiration rate, $\mathrm{PR}=$ Pulse rate

\section{Table 4: Spiro-metric analysis}

\begin{tabular}{|lll|}
\hline 4.1 Analysis of bronchodilating effect of salbutamol within each group (Wilcoxon Rank Test) & \\
& MDI & DPI \\
STD FVC & $2.14 \pm 0.51$ & $2.56 \pm 0.52$ \\
Baseline FVC & $0.92 \pm 0.72$ & $0.96 \pm 0.47$ \\
FVC after 30 mins of bronchodilator & $1.16 \pm .80$ & $1.18 \pm 0.52$ \\
FVC after 2 weeks of bronchodilator & $1.23 \pm 0.65$ & $1.26 \pm 0.45$ \\
p- value (FVC after30-FVC baseline) & 0 & 0 \\
p- value (FVC after two weeks-FVC baseline) & 0 & 0 \\
Std FEV1 & $1.78 \pm 0.48$ & $2.12 \pm 0.4$ \\
\hline Baseline FEV1 & $0.75 \pm 0.67$ & $0.75 \pm 0.42$ \\
FEV1after 30 mins of bronchodilator & $0.91 \pm 0.73$ & $0.88 \pm 0.41$ \\
FEV1after two weeks of bronchodilator & $0.95 \pm 0.52$ & $0.97 \pm 0.40$ \\
p- value (FEV1 after30-FEV1 Baseline) & 0 & 0.002 \\
p- value (FEV1 after two weeks-FEV1 Baseline) & 0 & 0 \\
\hline Std PEF & $318.93 \pm 42.97$ & $349.97 \pm 45.05$ \\
\hline Baseline PEF & $117.63 \pm 96.65$ & $110 \pm 76.33$ \\
\hline PEF after 30 mins of bronchodilator & $121.63 \pm 94.65$ & $116.86 \pm 64.11$ \\
\hline PEF after 2 weeks of bronchodilator & $134.4 \pm 82.61$ & $137.35 \pm 84.66$ \\
p- value (PEF after 30-PEF baseline) & 0.066 & 0.182 \\
\hline p- value (PEF after two weeks-PEF baseline) & 0.016 & 0 \\
\hline
\end{tabular}

Standard values are based on individuals' age, height and gender and automatically displayed by spirometer.

\begin{tabular}{|lccc|}
\hline 4.2 Comparison of improvement between two groups (Mann Whitney U Test) & & \\
Measures & MDI Group & DPI Group & $p$-Value \\
FEV1 & & & \\
Baseline & $0.75 \pm 0.67$ & $0.75 \pm 0.42$ & 0.268 \\
Improvement after 30 Mins & $0.16 \pm 0.18$ & $0.13 \pm 0.2$ & 0.295 \\
\hline Improvement after 2 weeks & $0.21 \pm 0.28$ & $0.22 \pm 0.24$ & 0.802 \\
FVC & & & \\
Baseline & $0.92 \pm 0.72$ & $0.96 \pm 0.47$ & 0.15 \\
\hline
\end{tabular}




\begin{tabular}{|llll|} 
Improvement after 30 Mins & $0.24 \pm 0.21$ & $0.21 \pm 0.23$ & 0.705 \\
Improvement after 2 weeks & $0.31 \pm 0.21$ & $0.30 \pm 0.25$ & 0.693 \\
\hline PEF & & & \\
Baseline & $117.63 \pm 96.6$ & $110 \pm 76.33$ & 0.988 \\
Improvement after 30 Mins & $4 \pm 45.3$ & $6.86 \pm 28.4$ & 0.802 \\
Improvement after 2 weeks & $16.77 \pm 41.8$ & $27.34 \pm 33.9$ & 0.448 \\
\hline
\end{tabular}

Improvement after 30 mins $=$ Post- bronchodilator values after 30 mins- Baseline values Improvement after two weeks $=$ Post- bronchodilator values after two weeks - Baseline values

Inhaler using Technique Score

Table 5: Understanding of the patients how to use the particular inhaler

\begin{tabular}{|llll|}
\hline Measures & MDI & DPI & p-Value \\
& Group & Group & \\
Placebo Score & $2.97 \pm$ & $4.87 \pm$ & \\
Score after & $8.6 \pm$ & 1.46 & 0.478 \\
counseling & 0.81 & $0.23 \pm$ & \\
Score in follow & $8.4 \pm$ & $9.47 \pm$ & 0.003 \\
up & 0.67 & 0.57 & 0 \\
\hline
\end{tabular}

Table 6 : Side effects associated with a particular device

\begin{tabular}{|lcc|}
\hline Measures & MDI (4) & DPI (7) \\
K-level & $3.33 \pm 0.09$ & $3.24 \pm 0.17$ \\
P-value & 0.001 & 0.004 \\
\hline
\end{tabular}

Table 7: Cost comparison of MDI and DPI

\begin{tabular}{|llc|}
\hline $\begin{array}{l}\text { Unit price per item } \\
\text { (Nepali Rupees) }\end{array}$ & MDI & DPI \\
$\begin{array}{l}\text { Cost of device } \\
\text { No of administration } \\
\text { per package }\end{array}$ & - & 27.00 \\
$\begin{array}{l}\text { Unit cost per } \\
\text { administration }\end{array}$ & 100 & 119.00 \\
$\begin{array}{l}\text { Cost of device per } \\
\text { dose * }\end{array}$ & & 30 \\
$\begin{array}{l}\text { Total cost per } \\
\text { administration }\end{array}$ & 1.48 & 0.9 \\
\hline
\end{tabular}

${ }^{*}$ Assuming Rotahaler device will last for 5 years.

\section{DISCUSSION}

Among the total Newars made up the highest population (32\%) followed by Brahmin (28\%). It was found that most of the patients were illiterate in both group, only about $7 \%$ in $\mathrm{MDI}$ and $20 \%$ in DPI were literate. Farmer constitutes the more than half of the population $(57 \%)$ followed by housewife (37\%).

The mean age of COPD patients was $61.20 \pm 13.52$ for MDI and $59.00 \pm 11.03$ for DPI group respectively. Both MDI and DPI users included in study have similar age as there is no significant difference ( $p$-value $0.318>0.05$; Mann-Whitney $\mathrm{U}$ test).

While analyzing among total no of Patients, most of the patients were having normal weight (57\%), while some of them $(35 \%)$ were categorized under underweight group as their BMI was $<18.5$ which is the prognostic factor for mortality.

Blood pressure, pulse rate, respiration rate and oxygen saturation were checked and analyzed in all patients before and after the use of bronchodilator within and between two groups. Baseline vital signs of both groups were similar ( $p$-value $>0.05$ ). There was no significant difference in baseline $B P, P R$ and $R R$ of the patients between two groups. After bronchodilator use, subjects in both groups showed similar BP, PR and RR. No significant difference between the devices was found in terms of vitals $(P>0.05$; Mann Whitney Test).

Both delivery systems i.e. MDI and DPI were found equally capable to produce bronchodilating effect of Salbutamol. All parameters FEV1, FVC and FEV1\% were significantly improved from baseline as the mean difference of these values between pre and post bronchodilator (after 30 minutes as well as after two weeks) were found significant, (P-values < 0.05 , Wilcoxon rank test; table 5.1). 
There were no significant differences between two groups in terms of improvement in FEV1, FVC and PEF level ( $P$ $>0.05$ ) after bronchodilator therapy. It proved there is the therapeutic equivalence between two delivery systems i.e. MDI and DPI at $200 \mu \mathrm{g}$ dose of Salbutamol (table 5.2).

Even though about $87 \%$ (52 out of 60 ) were already using the device to deliver the medicine their knowledge about the correct using technique seemed very low; $4.97 \pm$ 2.10 (MDI) \& $4.87 \pm 1.46$ (Rotahaler) when analyzed in Placebo. Most of them were given wrong instruction about the technique from medical shops outside the hospital (e.g. in some cases of Rotahaler, they were instructed to break the capsule by themselves and then poured into the Rotahaler for inhalation) and others who get correct instruction were also making many crucial mistakes. For example in case of MDI, not holding the device in upright position \& not closing the mouth properly so that fumes were seemed escaping from mouth were observed in most of the patients. In both groups (MDI as well as Rotahaler) exhalation before inhalation \& holding the breath after inhaling the medicine were missing. Studies also showed that many patients fail to hold inhaled medication in their lungs for the full 10 seconds, this final step in the inhaler technique is required for optimal pulmonary absorption of medication, regardless of type of device used.

Drug cost of unit dosage form for DPI was found to be lesser than that of MDI. The socioeconomic status of Nepalese people is low; particularly in the study area (Dhulikhel). The cost analysis would be helpful in recommending the affordable one between two therapeutically equivalent delivery systems. In this case, Rotahaler a simplest DPI was found to be therapeutically equivalent to MDI and is the cheaper one.

\section{CONCLUSION AND RECOMMENDATION}

The bronchodilator response was found to be similar irrespective of drug delivery system. ${ }^{17}$ It is possible that the DPI deposited the same amount of drug at the site of action as the MDI in patients with COPD. Intervention on inhaler technique improved the patient knowledge which is very crucial to achieve the definite therapeutic outcome. Though all patients showed similar skill at the initial stage $(p=0.478)$, the final score of inhalation technique was significantly improved in case of DPI $(p=0.003 ; 8.6 \pm 0.81$ for MDI Vs $9.23 \pm 0.68$ for DPI). Patients using Salbutamol are prone to suffer from hypokalemia in both patterns of delivery (for MDI $3.33 \pm 0.09 \mathrm{~mol} / / ; p$-value $=0.001$ and for DPI $3.24 \pm 0.17 \mathrm{~mol} / / ; p$-value=0.004).

The cost of treatment with DPI is found to be much lesser than that of MDI. Overall evidences from efficacy and cost analysis it seems that treatment of COPD patients with bronchodilator using DPI is more preferable than MDI even though both have similar clinical efficacy.

\section{RECOMMENDATIONS FOR PRACTICE INCLUDE:}

- Intervention is essential to improve inhalation technique.

- Nutrition intervention is essential as most of the patients are with $\mathrm{BMl}<21 \mathrm{~kg} / \mathrm{m}^{2}$ which is the major cause of morbidity.

- Potassium level should be checked in routine intervals there is a chance of hypokalemia.

- Even though both delivery systems have therapeutic equivalence, patient's choice should be given the first preference to improve the compliance.

- As the previous study as well as this study suggests therapeutic efficacy is dose dependent rather than device further research should be conducted at different doses with wide range at large population from two delivery systems.

\section{ACKNOWLEDGEMENT}

The authors would like to thank.

Assistant Professor Mrs. Rajani Shakya, Department of Pharmacy, Dr. Pankaj Pant, Department of Medicine, Dhulikhel Hospital, Mr. Dhiraj Giri, Assistant Professor Department of Mathematics, Dr Shibha Bahadur Karki. My humble regard and thank goes to all the patients whom I wish a quality life.

\section{REFERENCES}

1. http://www.lung.ca/diseases-maladies/copd.COPD. Canadian Lung Association 2008.

2. WHO media centre. COPD. Fact sheet $N^{\circ} 315$. May 2008

3. http://www.who.int/respiratory/copd. COPD. WHO 2008.

4. Sharma GK. Leading causes of mortality from diseases and injury in Nepal: a report from national census sample survey. J Inst Med 2006; 28:7-11. 
5. Bhushan Tuladhar and Kshitiz Shrestha. Environment and public health organization. Kathmandu, Nepal. December 2007

6. Nicola A Hanania and Amir Sharafkhaneh. Management of COPD. 2007

7. Fabbri LM, Hurd SS. Global Strategy for the Diagnosis, Management and Prevention of COPD. EurRespir J 2003; 22: $1-2$.

8. Patients UK. Inhalers for COPD; EMIS and PatientInformation Publication 2007. (http://www.patient.co.uk/)

9. Skrepnek, G.H. \& Skrepnek S.V. An assessment of therapeutic regimens in the treatment of acute exacerbations in chronic obstructive pulmonary disease and asthma. American Journal of Managed Care. 2004; 10(5 Suppl.), S139-S152.

10. Newton MF, O'Donnell DE, Forkert L. Response of lung volumes to inhaled salbutamol in a large population of patients with severe hypernation. Chest 2002; 121:104250.

11. http://www.surgeryencyclopedia.com/index.html. Spirometry test. National Lung Health Education Program 2007.
12. GOLD. Global strategy for the Diagnosis, management and Prevention of COPD.2007

13. Pauwels RA, Buist AS, Calverley PM, Jenkins CR, Hurd SS; GOLD Scientific Committee. Global strategy for the diagnosis, management, and prevention of chronic obstructive pulmonary disease: NHLBI/WHO Global Initiative for Chronic Obstructive Lung Disease (GOLD) Workshop summary. Am J Respir Crit Care Med. 2001; 163:1256-1276. (http://www.ncbi.nlm.nih.gov)

14. Chystyn $\mathrm{H}$. Is inhalation rate important for a dry powder inhaler using the in-check dial to identify these rates 2003; Respir Med 97:181-7.

15. S.P Newan. Inhaler treatment option in COPD. Eur Respir Rev 2005; 14:96,102-108

16. Van Manen JGE, Bindels PJE. The influence of COPD on health related quality of life dependent of the influence of comorbidity. J Clin Epidemiol. 2003;56:1177-1184

17. Lenney J, Innes JA, Crompton GK. Inappropriate inhaler use: assessment of use and patient preference of seven inhalation devices. Respir Med 2000; 94: 496-500. 